\title{
The prevalence of prostate cancer in Brazil is higher in Black men than in White men: systematic review and meta-analysis
}

\author{
Frederico R. Romero, Antonio W. Romero, Rui Manuel S. de Almeida, Renato Tambara Filho \\ Hospital de Clinicas da Universidade Federal do Paraná (FRR, RTF), Curitiba, Faculdade Assis Gurgacz \\ (FAG) (FRR,RMSA), Cascavel and Hospital Policlínica Cascavel (FRR, AWR), Cascavel, Brazil
}

\section{ABSTRACT}

Background: Black men have a higher incidence of prostate cancer compared with White men in several countries. In Brazil, most studies reported a similar prevalence of prostate cancer between Blacks and Whites as a result of the high race mixture of the population.

Objective: To perform a systematic review with meta-analysis of the prevalence of prostate cancer in Black versus White, Brown versus White, and Black versus Brown Brazilian men.

Design, Setting, and Participants: This systematic review included cohort, cross sectional and case-control studies comparing the prevalence of prostate cancer between races in Brazil. It was performed using an electronic search of references in bibliographic databases, and dissertations and theses databases from several Brazilian hospitals, universities, and schools of medicine. Meta-analysis was conducted using the RevMan software from the Cochrane Collaboration. To control for potential confounding variables, sensitivity analyses excluding case-control and cross sectional studies were performed.

Measurements: The outcomes of interest included the number of participants, prevalence of prostate cancer, and odds ratio of cancer between Black and White men, Brown and White men, and Black and Brown men.

Results and Limitations: : Twelve studies approaching the prevalence of prostate cancer in Black or Brown vs. White men in Brazil were identified, totalizing 41388 participants. The prevalence of prostate cancer was 9.6\% in Black vs. 5.6\% in White men (OR 1.58), 10.1\% in Black vs. 6.7\% in Brown men (OR 1.43), and 6.7\% in Brown vs. $6.6 \%$ in White men (OR 1.14). Limitations of this review reflect the complexity and ambiguity in the definition of who is Black and who is not in such an heterogeneous population like the Brazilian people.

Conclusions: This systematic review with meta-analysis demonstrates a higher prevalence of prostate cancer in Black men compared to White or Brown Brazilian men. The prevalence of prostate cancer is similar in Brown versus White men.

\section{ARTICLE INFO}

\section{Key words:}

Epidemiology; Prevalence; Prostatic neoplasms; Race relations

Int Braz J Urol. 2012; 38: 440-7

Submitted for publication: July, 21, 2011

Accepted after revision: February, 16, 2012

\section{INTRODUCTION}

Prostate cancer is the most common form of noncutaneous cancer in men and the second leading cause of male cancer mortality. The incidence of prostate cancer varies according to racial/ethnic differences in several countries (1). The estimated incidence of pros- 
tate cancer in Brazil was 54 per 100,000 men in 2010 (2).

Black men have a higher incidence compared with White men, particularly in North America $(1,3,4)$ and the stage of prostate cancer at diagnosis may be more advanced in Black patients (5-10). American Urological Association recommends that African American men that wish to be tested, together with those men with first-degree relatives with prostate cancer history, should begin prostate cancer screening at the age of 40 . White men and those with no family history may begin screening at 45 years of age.

In Brazil, most published studies did not demonstrate statistically significant difference in the prevalence of prostate cancer between White and Black patients.(11-16) These results have been frequently attributed to the high race mixture index of the Brazilian population as a consequence of centuries of interethnic crosses between Europeans, Africans, and Amerindians; as well as the use of different methodology to classify individuals into racial groups and the inaccuracy in stratification of race using skin color $(3,5,11-13,15,17,18)$.

In contrast to the bifurcated US model, where Blacks and Whites are clearly separate groups, with Blacks defined as those with any African ancestry ("one-drop" or hypodescent rule), racial classification in Brazil is far more complex, ambiguous, and fluid. The Brazilian model includes an intermediate Brown (pardo) category along a white-to-black color continuum, often used as a proxy for mulattos or persons with White and Black admixture (19). The 2010 Census demonstrated that 43.7\% of Brazilian men self-reported to be Brown.

The primary objective of this systematic review with meta-analysis is to evaluate odds ratio and confidence intervals of the prevalence of prostate cancer in Black men compared to White men in Brazil. Secondarily, we evaluated if there is distinction of the prevalence of prostate cancer in Black versus Brown, and Brown versus White Brazilian men.

\section{MATERIALS AND METHODS}

This review included cohort, cross-sectional and case-control studies comparing the prevalence of prostate cancer between Black and White men, Brown and White men, and Black and Brown men in Brazil. Participants were men older than 40 years undergoing population or community-based prostate cancer screening, men attending a Urology service in a hospital or an outpatient basis, or the records of prostate biopsy and cancer from hospitals, clinics, laboratories, and autopsy services.

The review was performed using the following databases: BIREME, CAPES, LILACS, PUBMED, scholar Google, and SciELO. The following Mesh search headings were used: "prostate cancer screening, and Brazil", "prostate cancer, race, and Brazil", "prostate cancer, ethnic, and Brazil", "prostate cancer, black, and Brazil", "prostate cancer, white, and Brazil", and "prostate cancer, epidemiology, and Brazil". The "related articles" function was used to broaden the search, and all abstracts, studies, and citations scanned were reviewed.

A search was also performed in dissertations and theses databases available on-line from several Brazilian hospitals, universities, and schools of medicine, including: HOSPITAL A.C. Camargo, INCA (National Cancer Institute), PUC Brasília (Catholic University of Brasilia), PUC-PR (Catholic University of Parana), PUC-RS (Catholic University of Rio Grande do Sul), PUC-SP (Catholic University of Sao Paulo), UERJ (State University of Rio de Janeiro), UFBA (Federal University of Bahia) , UFJF (Federal University of Juiz de Fora), UFMA (Federal University of Maranhao), UFMG (Federal University of Minas Gerais), UFMS (Federal University of Mato Grosso do Sul), UFPel (Federal University of Pelotas, RS), UFPR (Federal University of Parana), UFRB (Federal University of Bahia Reconcavo), UFRGS (Federal University of Rio Grande do Sul), UFRJ (Federal University of Rio de Janeiro), UFRN (Federal University of Rio Grande do Norte), UNB (University of Brasilia), UNESP (University Estadual Paulista), UNICAMP (University of Campinas), UNIFESP (Federal University of Sao Paulo), and USP (University of Sao Paulo).

References of all pertinent manuscripts were manually searched for additional possibilities.

To enter the review, studies had to be conducted in a Brazilian population and to compare 
the prevalence of prostate cancer in Black or Brown versus White men. A Microsoft ${ }^{\circledR}$ Excel $^{\circledR}$ database was specifically design for study purposes. The following information were collected: study design, number of participants, prevalence of prostate cancer, methodology of data collection, racial/ethnic/ color definition, and effect estimates with 95\% confidence intervals (95\% CI). We excluded the studies in which any of the outcomes of interest was not reported or could not be calculated based on the published results.

Meta-analysis was conducted using the Review Manager software (version 5) from the Cochrane Collaboration, and a pooled odds ratio was calculated as a standard plot with 95\% CI using the Mantel-Haenszel method.

The degree of statistical homogeneity between the studies was assessed by using the modified chi-square test (Cochran's Q) which, by convention, indicates the presence of heterogeneity when $p>0.10$. When there was no heterogeneity between individual trials, a fixed-effect model was used. If heterogeneity was present, a random-effect model was used. To control for potential confounding variables, sensitivity analyses excluding case-control and cross sectional studies were performed.

To evaluate for potential publication bias on the results of our meta-analysis, we constructed a funnel plot as a quality-control assessment.

\section{RESULTS}

We identified 12 studies approaching the prevalence of prostate cancer in Black versus White men in Brazil: seven cohort studies with a median number of 970 men (range 304 to 2697); four cross sectional studies with a median number of 186 men (range 119 to 300); and one case-control study with 29,460 men.

The average prevalence of prostate cancer was 5\% (range 1.3\% to 16.6\%) in the population undergoing screening (cohort studies). In the studies evaluating prostate biopsy/pathology specimens (cross sectional and case-control studies) the prevalence of prostate cancer was $17.4 \%$ (range 6.3\% to 34.0\%).

Four studies in this systematic review used self-identification (color choice made by the respondent) as the methodology to classify the participants in different racial/ethnic groups $(5,14,15,20)$. All other studies apparently used hetero-identification (color attribution assigned by the interviewer to the respondent).

Some studies included as Black people who were classified as Brown or Black, $(3,11,12)$ and others grouped in the Black category all nonWhite participants.(15,20-22) One study included as Black individuals with all kinds of skin pigmentation if they had African ancestry.(5).

Overall, the prevalence of prostate cancer in 2740 Black men was 9.6\%, compared to $5.6 \%$ in 35506 White men (OR 1.58, CI 95\% 1.25-1.98, $\mathrm{p}$ for overall effect $<0.05, \mathrm{p}$ for heterogeneity $>0.10$, Figure -1 ).

Based on five studies that evaluated the prevalence of prostate cancer in Brown men independently $(3,5,11,12)$, the prevalence of prostate cancer was $10.1 \%$ in 1757 Black men, compared to $6.7 \%$ in 2568 Brown men (OR 1.43, CI 95\% $1.14-1.79$, $p$ for overall effect $<0.05, p$ for heterogeneity $>0.10$ ). Odds ratio of prostate cancer in Brown versus White men was 1.14 (CI 95\% 0.78$1.67, \mathrm{p}$ for overall effect $>0.05, \mathrm{p}$ for heterogeneity $>0.10$, Figure-2).

When only the best quality (cohort) studies were analyzed, excluding case-control and cross sectional studies, odds ratio of prostate cancer prevalence in Black men versus White men was 1.73 (CI 95\% 1.18-2.54, p for overall effect $<0.05$, $\mathrm{p}$ for heterogeneity $>0.10$ ); Black versus Brown, 1.50 (CI 95\% 1.02-2.19, p for overall effect $<0.05$, p for heterogeneity $>0.10$ ); and Brown versus White, 1.07 (CI 95\% 0.57-2.00, p for overall effect $>0.05, p$ for heterogeneity $>0.10$, Figure-3).

Figure- 4 show the funnel plot analysis to evaluate for potential publication bias. The shape of the funnel plot seemed to be asymmetrical, suggesting that potential publication bias might affect the findings of our meta-analysis.

\section{DISCUSSION}

Given the uncertainty about the benefits of population-based screening, informed decision making about prostate cancer screening, providing individual patients with current information 
Figure 1 - Comparison between the prevalence of prostate cancer in Black versus White men in Brazil.

\begin{tabular}{|c|c|c|c|c|c|c|c|c|c|c|}
\hline \multirow{2}{*}{ Study or Subgroup } & \multicolumn{2}{|c|}{ Black } & \multicolumn{2}{|c|}{ White } & \multicolumn{3}{|c|}{ Odds Ratio } & \multirow{2}{*}{\multicolumn{2}{|c|}{$\begin{array}{c}\text { Odds Ratio } \\
\text { M-H, Random, } 95 \% \mathrm{Cl}\end{array}$}} & \\
\hline & Events & Total & Events & Total & Weight & M-H, Random, 95\% Cl & & & & \\
\hline ALVAREZ 2007 & 5 & 63 & 3 & 56 & $2.3 \%$ & $1.52[0.35,6.68]$ & & & $=$ & \\
\hline ANTONOPOULOS 2001 & 16 & 371 & 60 & 2326 & $11.7 \%$ & $1.70[0.97,2.99]$ & & & $\bullet$ & \\
\hline ANTONOPOULOS 2002 & 11 & 189 & 28 & 1149 & $8.2 \%$ & $2.47[1.21,5.06]$ & & & $\longrightarrow$ & \\
\hline BARROS 2003 & 37 & 188 & 16 & 116 & $9.8 \%$ & $1.53[0.81,2.90]$ & & & 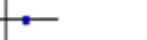 & \\
\hline BIAZZI 2010 & 30 & 88 & 66 & 212 & $12.8 \%$ & $1.14[0.67,1.94]$ & & & $\leftarrow$ & \\
\hline BOUCHARDY 1991 & 110 & 1100 & 1626 & 28360 & $30.3 \%$ & $1.83[1.49,2.24]$ & & & $=$ & \\
\hline GLINA 2001 & 2 & 202 & 17 & 1140 & $2.3 \%$ & $0.66[0.15,2.88]$ & & & & \\
\hline MAGRINI 2001 & 12 & 25 & 72 & 212 & $6.4 \%$ & $1.79[0.78,4.13]$ & & & & \\
\hline MARTINS 2000 & 1 & 58 & 23 & 852 & $1.3 \%$ & $0.63[0.08,4.77]$ & & & & \\
\hline PASCHOALIN 2003 & 20 & 235 & 1 & 148 & $1.3 \%$ & $13.67[1.82,103.01]$ & & & & \\
\hline ROMERO 2011 & 9 & 176 & 26 & 794 & $7.2 \%$ & $1.59[0.73,3.46]$ & & & & \\
\hline SCHMITT 2009 & 9 & 45 & 36 & 141 & $6.5 \%$ & $0.73[0.32,1.66]$ & & & - & \\
\hline Total $(95 \% \mathrm{CI})$ & & 2740 & & 35506 & $100.0 \%$ & $1.58[1.25,1.98]$ & & & $\diamond$ & \\
\hline Total events & 262 & & 1974 & & & & & & & \\
\hline $\begin{array}{l}\text { Heterogeneity: } \operatorname{Tau}^{2}=0.0 \\
\text { Test for overall effect: } Z=\end{array}$ & $\begin{array}{l}\mathrm{Chi}^{2}=1 \\
88(\mathrm{P}=\end{array}$ & $\begin{array}{l}4.49, d \\
.0001)\end{array}$ & $f=11(P=$ & $=0.21) ;$ & $\left.\right|^{2}=24 \%$ & & 0.01 & 0.1 White ${ }^{1}$ & ${ }_{\text {Black }}^{10}$ & 100 \\
\hline
\end{tabular}

Figure 2 - Comparison between the prevalence of prostate cancer in Black versus Brown and Brown versus White Brazilian men.

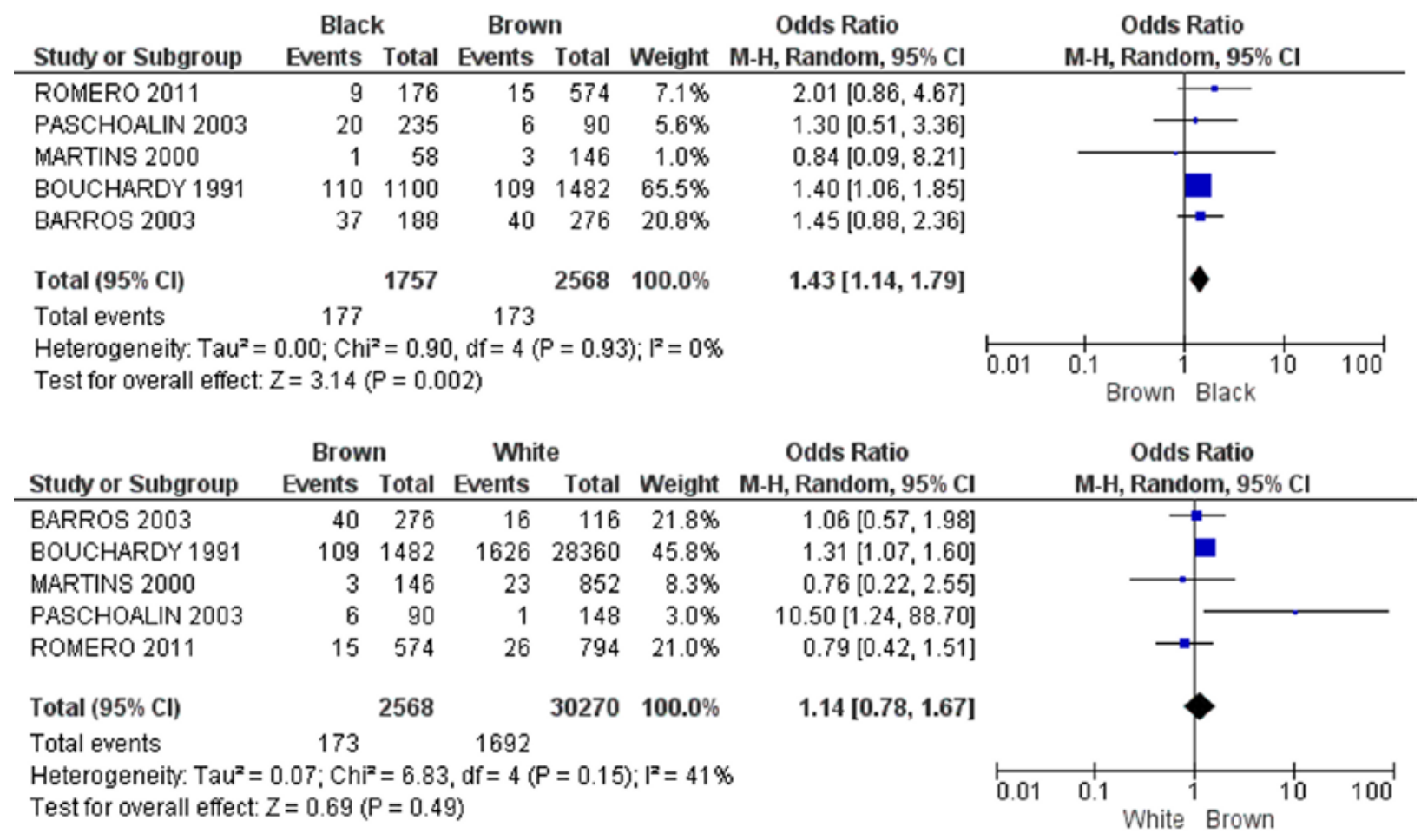


Figure 3 - Comparison of cohort studies evaluating the prevalence of prostate cancer in Black versus White, Brown versus White, and Black versus Brown men in Brazil.

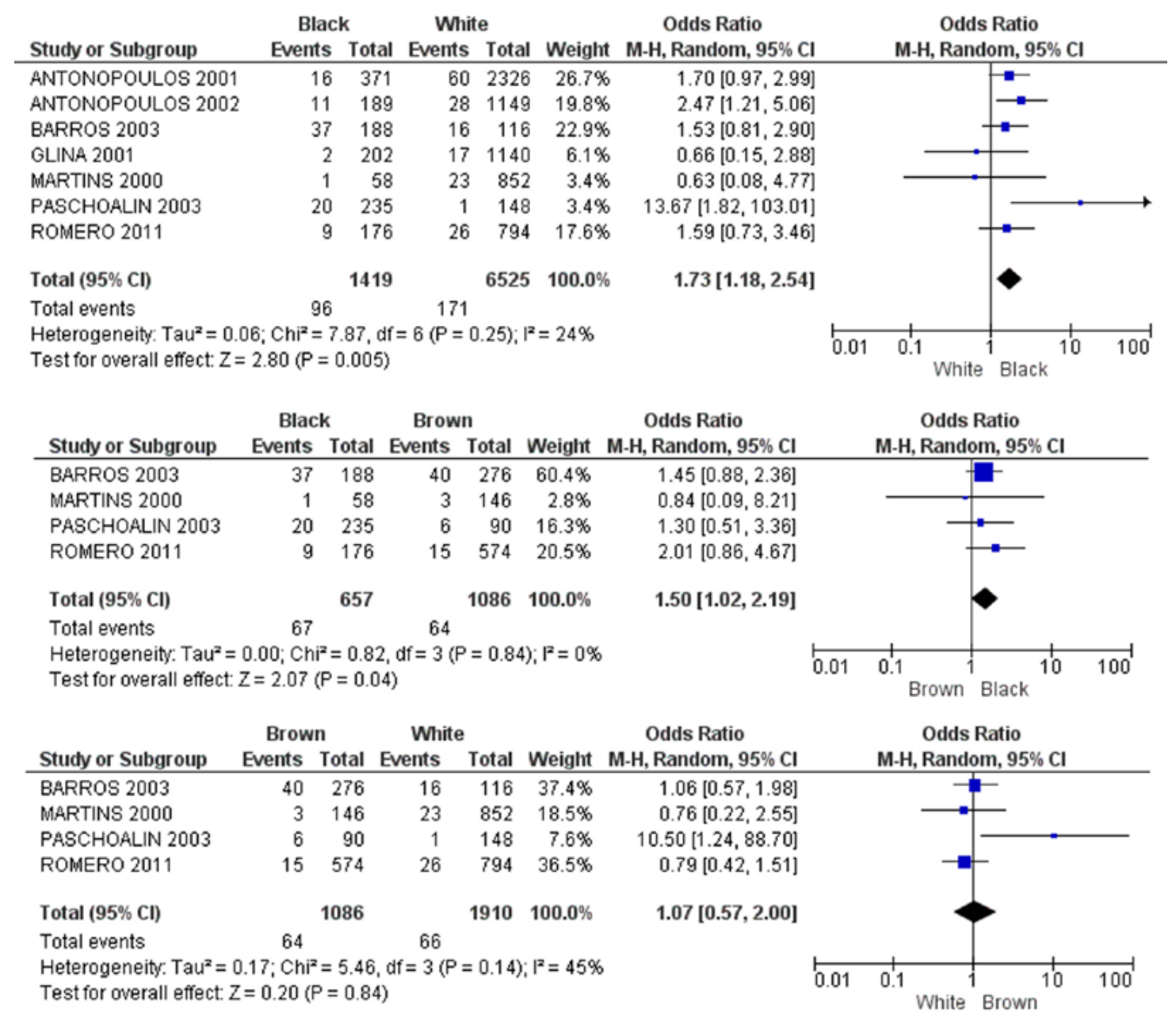

Figure 4 - Funnel plot of all studies, including cohort, case-control, and cross-sectional studies.

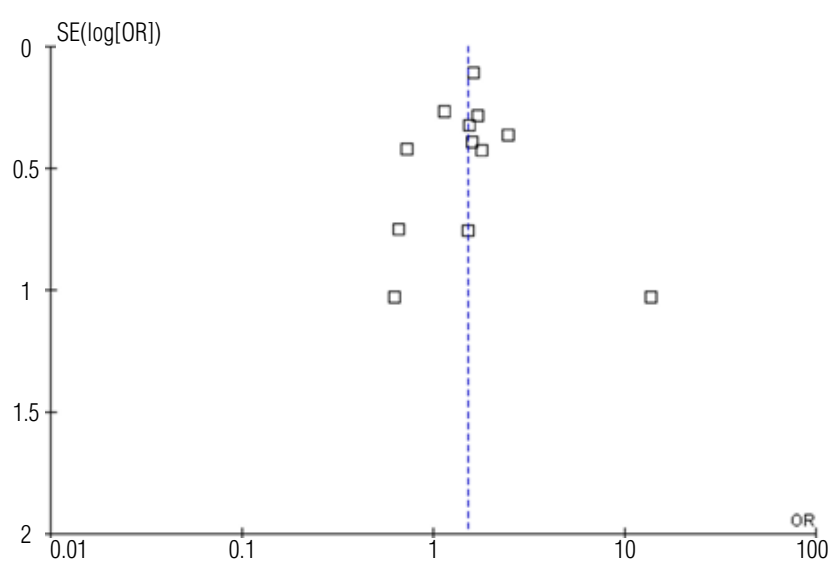

including the benefits and risks is recommended by several urological associations and agencies around the world. Orientation should include early diagnosis, the risks of overdiagnosis and overtreatment, as well as documented risk factors such as age, family history, and race/ethnicity.

In Brazil, most published studies did not separately demonstrate a statistically significant difference in the prevalence of prostate cancer in Black versus White patients $(11-16,21,22)$. Notwithstanding, several of these studies showed a tendency toward a higher prevalence of prostate cancer in Black men $(11,13,21)$, suggesting that a low sample bias may have been responsible for non-significant statistical results. 
According to the sample size estimator with continuity correction factor by Fleiss, the minimum number of participants necessary for statistical significance with a level of confidence of 95\% among 6/12 studies retrieved in this systematic review would have to be between 1,064 and 25,698 participants. With a median population of 910 (range 119 to 29460) participants in the studies identified in this systematic review, the sample sizes of most studies were not large enough for statistical significance.

Taken together, these studies provided that the prevalence of prostate cancer in Brazil is $58 \%$ higher in Blacks, and 43\% higher in Browns, compared to White men, with a confidence level of 95\%.

Interestingly, funnel plot analysis of the present meta-analysis indicated publication bias, even though this effect refers to the tendency of reporting results that are positive, and 9/12 selected studies in this meta-analysis had negative/ inconclusive results.

When sensitivity analyses excluding casecontrol and cross sectional studies were performed, the results showed a sound 73\% higher prevalence of prostate cancer in Black men compared to White men in Brazil, similar to several studies from the United States, Canada, Caribbean, and England.(3,4,6,22,23).

The exclusion of case-control and crosssectional studies maintained a higher prevalence of prostate cancer in Black versus Brown men, but demonstrated a similar prevalence between Brown and White men. These outcomes may be partially explained by the scarce number of studies evaluating racial/ethnic/color influences on prostate cancer prevalence in Brazil, and the relatively small sample size in each study, especially for a cancer prevalence of $1.3 \%$ to $5.7 \%$ and a median proportion of Black and Brown participants of only $11.4 \%$ and $19 \%$, respectively $(5,11,12,13,17)$.

Other limitation of this review reflects the complexity and ambiguity of the definition of who is Black and who is not in such an heterogeneous population like the Brazilian people. In Brazil, race/ethnic origin is usually based on skin color and other physical characteristics such as facial features, hair texture, and the shape of the lips and nose. Race, ethnicity, and color are frequently used interchangeably $(19,21)$. However, anthropometric features are considered a poor indication of ancestry because these oligogenic traits are believed to have emerged as adaptations to geographical selective factors such as solar radiation and heat (18). In contrast with the situation in the US and Europe, there appears to be no racial descent rule operational and it is possible that two siblings differing in color be assigned to completely diverse racial/ethnic categories $(18,24)$.

At the same time, Brazilian approaches to race have had significant implications on individuals' economic conditions, with the Black population having a less favorable social situation, with lower access to education, poorer conditions of living, higher unemployment rates, and decreased income. As a result of the widespread social prejudice and discrimination, wealthy people with a darker complexion usually associate their skin color with Amerindian rather than African ancestry, and a large study showed that only about 10\% of black Brazilians consider themselves of African origin (24), although it is known there is a large number of Brazilians that do have some African ancestry (5). Therefore, the terms "African Brazilian" and "African descendent", commonly used in North-America, are usually restricted to formal discourse in Brazil, and they are almost never used in informal language $(18,21,24)$.

Although there is an enormous variety of racial/ethnic/color terms in use in Brazil (19), the established color categories in the Brazilian census since 1940 are White, Black, Brown, and Yellow. Brown is used for all those colors that do not fit the Black, White, or Yellow variables $(21,25)$. In practical terms, it describes people who have a skin darker than Whites and lighter than Blacks, but not necessarily implies a Black-White mixture since it may include Amerindians descendants. Therefore, the Brown category may be subdivided in several groups such as mulattos (Black and White origin), caboclos (Amerindian and White origin), and cafuzos (Amerindian and Black origin). Brown individuals may also be grouped together with Blacks as Negro or Black, but there is still no consensus in the Brazilian society $(19,25)$. 
As a reflex of this controversy, the studies identified in this systematic review used different criteria to classify men in the diverse racial/ethnic/ color groups.

Another limitation of this review concerns to the methodology of classification in each color category. In Brazil, where race/ethnic/color categories are abstract, having been constructed from a combination of physical characteristics, social status, and regional origin, the objectivity of color attribution is questionable, with respondents (selfidentification) and interviewers (hetero-identification) being risked to change their response from one interview to another(19,21,25). Responses may reflect the social meaning that color holds either for those collecting the data or for those interviewed, what may have been responsible for the tendency in the growing proportion of Brazilians who self-report to be Brown in the last decade. Furthermore, the color of the interviewer may influence the classification process. One study showed that $89.3 \%$ percent of subjects were identified as White by a white staff, while a black staff identified only $26.2 \%$ of those same subjects as being White (25).

Implications of the present study include the guidance for a larger sample size in future surveys evaluating the prevalence of prostate cancer in different race/ethnic/color groups. More objective forms of classification including skin reflectance spectrophotometry may be used to avoid bias, although measuring only skin pigmentation fails to take into considerations other qualities that contribute to the complex color trait (18). Upcoming studies should also evaluate the possible risk factors for the higher prevalence of prostate cancer in the Black male population in Brazil and other South-American countries, and whether there is a difference between Black and White men regarding PSA values, staging and grading of prostate cancer at diagnosis, and the risk of dying from prostate cancer.

Although the best method to qualify an individual race/ethnic origin is based on the composition of nuclear and mitochondrial DNA (5), this review shows evidence that the intricate, commonly used classification of race/ethnic origin using skin color and anthropometric features may be clinically useful for prostate cancer risk stratification in Brazil.

\section{CONCLUSIONS}

This systematic review with meta-analysis demonstrates a higher prevalence of prostate cancer in Black men compared to White men in Brazil. Secondarily, the prevalence of prostate cancer is higher for Black versus Brown Brazilian men. The prevalence of prostate cancer is similar in Brown versus White men.

\section{CONFLICT OF INTEREST}

None declared.

\section{REFERENCES}

1. Miller BA, Kolonel LN, Bernstein L, Young Jr. JL, Swanson GM, West D, et al., eds. Racial/ ethnic patterns of cancer in the United States 1988-1992. Bethesda, Maryland, United States of America: National Cancer Institute; 1996. (NIH Pub. No. 96-4104).

2. Estimate 2010: Incidence of cancer in Brazil [eletronic]. Rio de Janeiro: Brazilian National Cancer Institute; 2010. Last accessed July 20, 2011. Available from: http://www.inca. gov.br/estimativa

3. Bouchardy C, Mirra AP, Khlat M, Parkin DM, de Souza JM, Gotlieb SL. Ethnicity and cancer risk in São Paulo, Brazil. Cancer Epidemiol Biomarkers Prev. 1991 Nov-Dec; 1: 21-7.

4. Ben-Shlomo Y, Evans S, Patel B, Anson K, Muir G, Persad $R$ et al. Differences in the epidemiology and presentation of prostate cancer in Black and White men in England: lessons learnt from the process study. BJU Int. 2009 Mar; 103: 723-4.

5. Paschoalin EL, Martins AC, Pastorello M, Sândis KA, Maciel LM, Silva WA Jr et al. Racial influence on the prevalence of prostate carcinoma in Brazilian volunteers. Int Braz $\mathrm{J}$ Urol. 2003 Jul-Aug; 29: 300-5.

6. Barroso U Jr, Gomes de Oliveira J, Barroso AV, Pontes JE, Power IJ. Differences in epidemiologic, biologic, clinical, and pathologic behavior of prostate cancer in Black and White Americans. J Bras Urol, 1999; 25: 53-58.

7. Polednak AP, Flannery JT. Black versus white racial differences in clinical stage at diagnosis and treatment of prostatic cancer in Connecticut. Cancer. 1992 Oct 15; 70: 2152-8.

8. Steele GD Jr, Osteen RT, Winchester DP, Murphy GP, Menck HR. Clinical highlights from the National Cancer Data Base: 1994. CA Cancer J Clin. 1994 Mar-Apr; 44: 71-80. 
9. Coleman MP, Quaresma M, Berrino F, Lutz JM, De Angelis $\mathrm{R}$, Capocaccia $\mathrm{R}$ et al. CONCORD Working Group. Cancer survival in five continents: a worldwide population-based study (CONCORD). Lancet Oncol. 2008 Aug; 9: 730-56.

10. Du XL, Lin CC, Johnson NJ, Altekruse S. Effects of individual-level socioeconomic factors on racial disparities in cancer treatment and survival: findings from the National Longitudinal Mortality Study, 1979-2003. Cancer. $2011 \mathrm{Jul}$; 117: 3242-51.

11. Barros MS, Silva VR, Santos GB, Hughes A, Silveira MA. Prevalence of prostate adenocarcinoma according to race in an university hospital. Int Braz J Urol. 2003 Jul-Aug; 29: 306-11.

12. Martins AC, Reis RB, Suaid HJ, Maciel LM, Cologna AJ, Falconi RA. Screening for carcinoma of the prostate in volunteers. Int Braz J Urol. 2000; 26: 516-22.

13. Antonopoulos IM, Pompeo ACL, Hayek OR, Sarkis AS, Alfer W Jr, Arap S. Results of prostate cancer screening in nonsymptomatic men. Braz. J. Urol, 2001; 27: 227-34.

14. Glina S, Toscano IL Jr, Mello JF, Martins FG, Vieira VL, Damas CG. Results of screening for prostate cancer in a community hospital. Int Braz J Urol. 2001; 27: 235-43.

15. Biazzi F. [Characteristics of the patients undergoing US-guided transrectal prostate biopsy with PSA determination lower or equal to $4.0 \mathrm{ng} / \mathrm{ml}$ ]. [Master degree dissertation]. Botucatu (SP): Universidade Estadual Paulista "Julio de Mesquita Filho"; 2010.58 p. Web site available at In: http://www.athena. biblioteca.unesp.br/exlibris/bd/bbo/33004064006P8/2010/ biazzi_f_me_botfm.pdf. Portuguese.

16. Dini LI, Koff WJ. [Profile of prostate cancer at the general hospital of Porto Alegre]. Rev Assoc Med Bras. 2006 JanFeb; 52: 28-31.

17. Antonopoulos IM, Pompeo AC, Goes PM, Chade J, Sarkis AS, Arap S. Racial differences in prostate cancer prevalence. Int Braz J Urol. 2002 May-Jun; 28: 214-20.

18. Parra FC, Amado RC, Lambertucci JR, Rocha J, Antunes CM, Pena SD. Color and genomic ancestry in Brazilians. Proc Natl Acad Sci U S A. 2003 Jan; 100: 177-82.

19. Telles EE. Race in another America: the significance of skin color in Brazil. Princeton, NJ: Princeton University Press, 2004. 324 p.
20. Schmitt CS. [Serum levels of hypothalamic-hypofisarytesticular axis hormones in men with or without prostate cancer]. [Master degree dissertation]. Porto Alegre (RS): Universidade Federal do Rio Grande do Sul; 2009. 81 p. Web site available at In: http://www.lume.ufrgs.br/bitstream/handle/10183/21049/000735493.pdf?sequence $=1$. Last accessed July 20, 2011. Portuguese.

21. Magrini E. [Transrectal prostate biopsy: correlation between digital rectal examination, ultrasonography, prostate specific antigen, and adenocarcinoma]. [Master degree dissertation]. Campinas (SP): Universidade Estadual de Campinas 2001. Web site available at In: http://www.bibliotecadigital.unicamp.br/document/?code=vtls000231002. Last accessed July 20, 2011. Portuguese.

22. Alvarez GA. [Frequency of prostate cancer in renal transplant patients: case-control study]. [Master degree dissertation]. São Paulo (SP): Universidade de São Paulo; 2007. Web site available at In: http://www.teses.usp.br/teses/ disponiveis/5/5153/tde-17022009-105331/es.php. Last accessed July 20, 2011. Portuguese.

23. Jack RH, Davies EA, Møller H. Prostate cancer incidence, stage at diagnosis, treatment and survival in ethnic groups in South-East England. BJU Int. 2010 May; 105: 1226-30.

24. Schwartzman S. [Out of focus: ethnical diversities and identities in Brazil]. Web site available at In: http://www. schwartzman.org.br/simon/pdf/origem.pdf. Last accessed July 20, 2011. Portuguese.

25. Piza E, Rosemberg F. Color in the Brazilian census. In: Race in contemporary Brazil: from indifference to inequality. Reichmann R, editor. University Park: the Pennsylvania State University Press; 1999: 37-52. 